\title{
Fibroepithelial Lesion Initially Believed to Be Fibroadenoma, but Interval Growth Consistent With Phyllodes Tumor
}

\author{
Quan D. Nguyen ${ }^{1}$, Samuel O. Krider ${ }^{2}$, James T. Roberts ${ }^{2}$, Flavia E. Posleman Monetto ${ }^{1}$, Jing He $^{3}$ \\ 1. Radiology, University of Texas Medical Branch, Galveston, USA 2. Diagnostic Radiology, University of Texas Medical \\ Branch, Galveston, USA 3. Pathology, University of Texas Medical Branch, Galveston, USA
}

Corresponding author: Quan D. Nguyen, qunguyen@utmb.edu

\begin{abstract}
Fibroepithelial lesions of the breast are commonly encountered tumors comprised of stromal and epithelial components. Fibroadenoma and phyllodes tumor are both fibroepithelial lesions, but their management differs. Phyllodes tumor requires surgical excision, whereas fibroadenoma requires no further workup. Both have many overlapping histological features making it difficult to distinguish between a benign fibroadenoma versus the more aggressive phyllodes tumor. This case details a breast mass that was initially believed to be a fibroadenoma, but interval growth at one year follow up resulted in surgical excision with final pathology revealing phyllodes tumor.
\end{abstract}

Categories: Medical Education, Radiology, Oncology

Keywords: fibroadenoma, phyllodes, fibroepithelial, mammogram, breast mass, breast cancer, ultrasound, breast cancer screening

\section{Introduction}

Fibroepithelial lesions of the breast occur in approximately 10-15\% of women [1]. Phyllodes tumors of the breast account for $0.3 \%$ to $1 \%$ of all primary breast tumors and constitute $2.5 \%$ of all fibroepithelial tumors $[2,3]$. Phyllodes tumors are graded according to recommendations by the World Health Organization as benign, borderline, or malignant based on the presence of stromal cellularity, atypia, mitotic activity, border infiltrations versus circumscription, and stromal overgrowth [4-6]. While benign and borderline phyllodes tumors demonstrate a good prognosis and low rates of recurrence, malignant phyllodes tumors often metastasize, exhibit poor clinical prognosis, and demonstrate high rates of recurrence. Given such clinical variability, accurate grading, and differentiation of phyllodes tumors are imperative. Grading requires evaluation of the entire lesion and should be based on excision specimens [6-8].

Received 07/10/2020 Review began 07/10/2020 Review ended 09/06/2020 Published 09/10/2020

(c) Copyright 2020 Nguyen et al. This is an open access article distributed under the terms of the Creative Commons Attribution License CC-BY 4.0., which permits unrestricted use, distribution, and reproduction in any medium, provided the original author and source are credited.

\section{Case Presentation}

A 64-year-old woman with a past medical history of type 2 diabetes mellitus and hypertension presented for her annual bilateral screening mammogram. The patient reported no relevant family, medical, or surgical history. Screening mammogram images of the left breast demonstrated a $17 \mathrm{~mm}$ oval-shaped mass with circumscribed margins at the three o'clock position in posterior depth, $13 \mathrm{~cm}$ from the nipple (Figure 1). Targeted ultrasound of the right breast demonstrated an oval-shaped hypoechoic circumscribed mass measuring $15 \times 9 \times 12 \mathrm{~mm}$ at three o'clock, $13 \mathrm{~cm}$ from the nipple with the orientation that is parallel to the skin (Figure 2). An ultrasound-guided core biopsy of the breast mass was performed with pathology revealing a fibroepithelial lesion favoring fibroadenoma, although phyllodes tumor could not be ruled out (Figure 3). 


\section{Cureus}

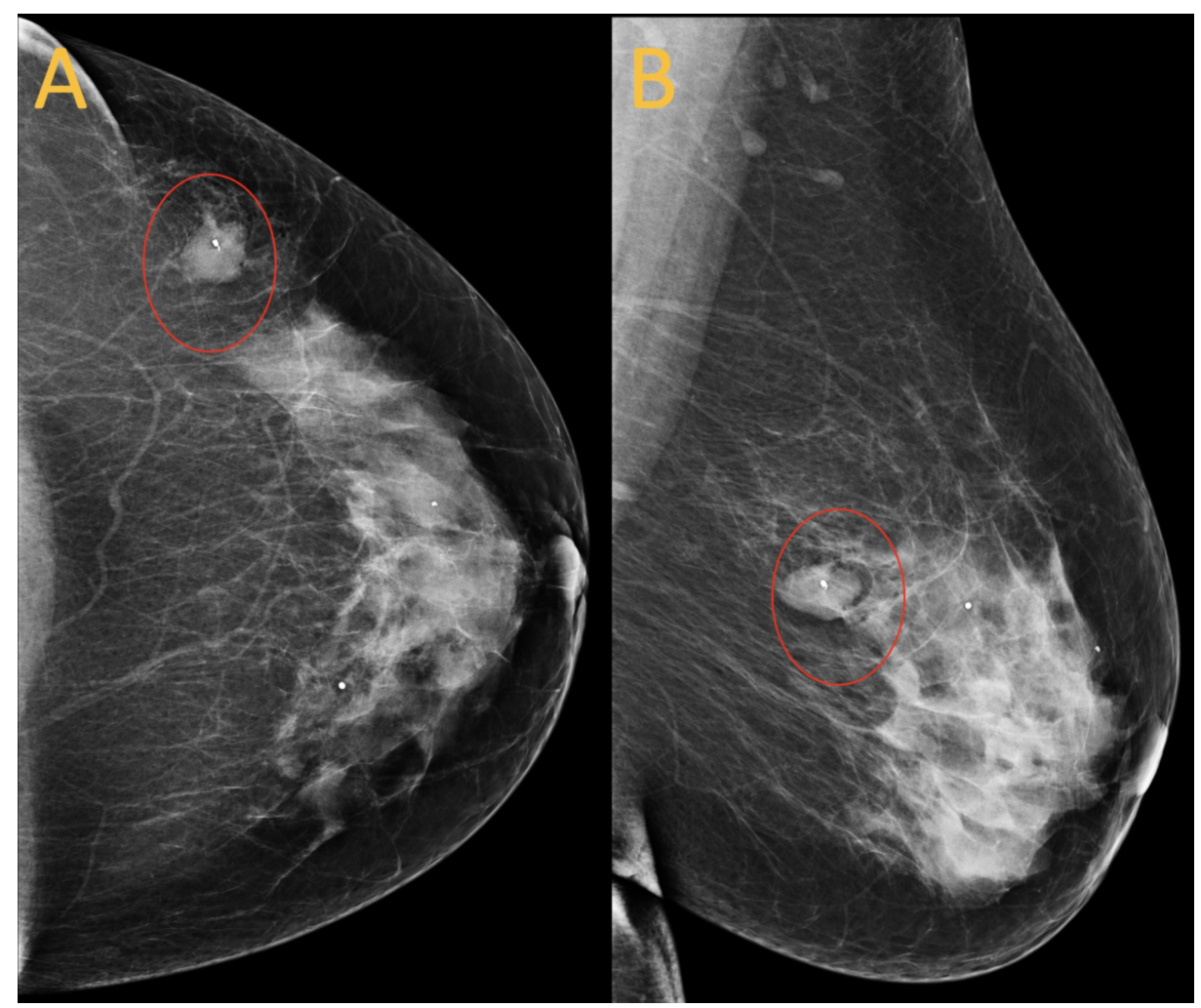

FIGURE 1: Initial post-biopsy mammogram

Images show left breast oval mass with circumscribed margins measuring $15 \mathrm{~mm}$ (red circles). A mammogram was performed in January 2019.

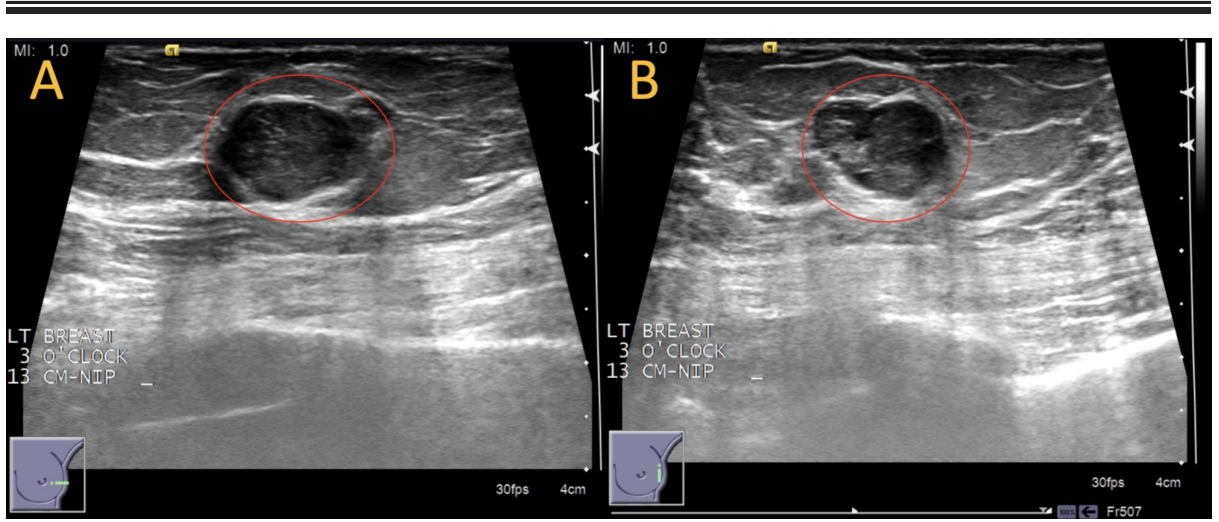

FIGURE 2: Left breast diagnostic ultrasound

Images show left breast oval mass with circumscribed margins measuring $15 \mathrm{~mm}$ (red circles). An ultrasound was performed in January 2019. 


\section{Cureus}

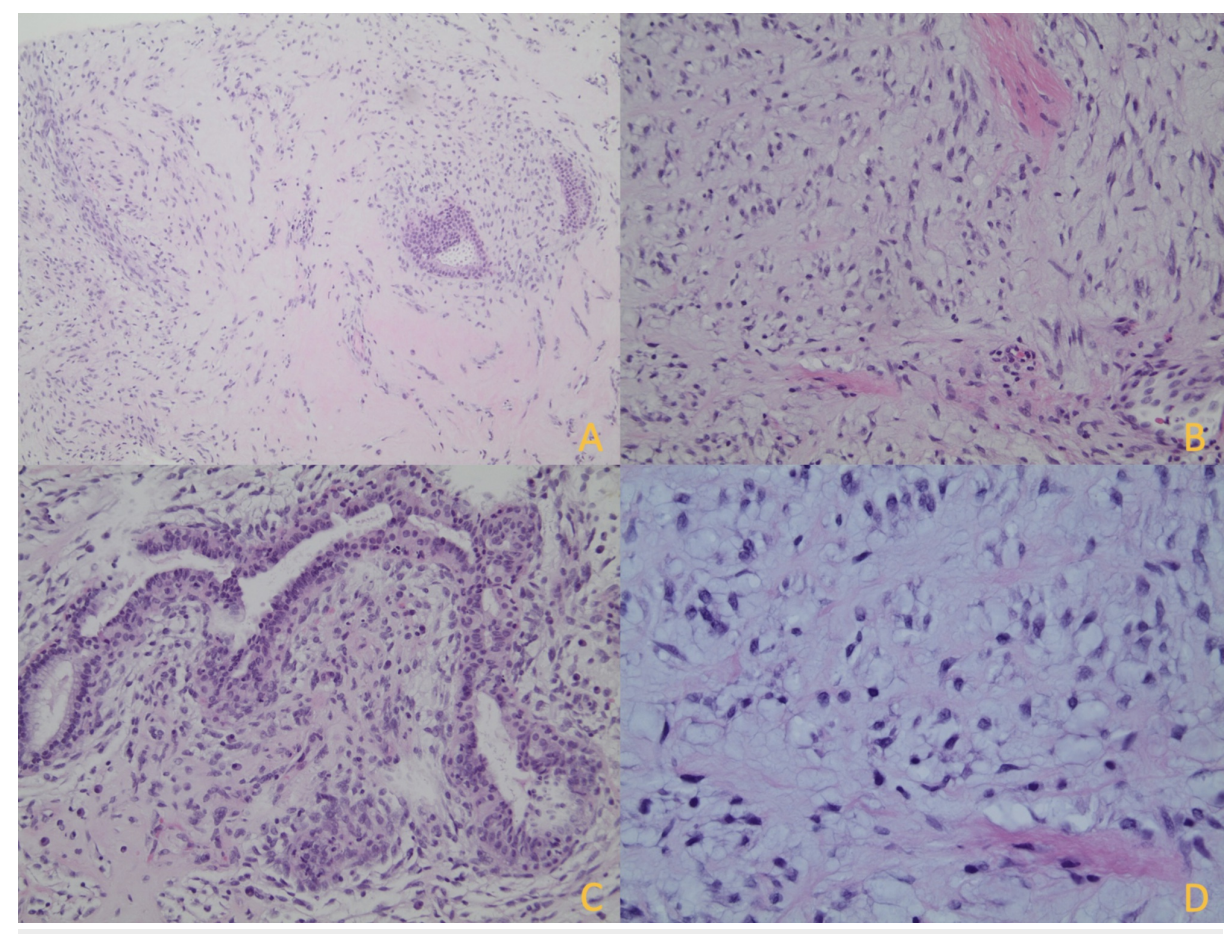

FIGURE 3: Histological findings of biopsy of the breast mass

A: An ultrasound-guided core biopsy of the breast mass shows a fibroepithelial lesion with alternating hypercellular and hypocellular stroma (magnification $\times 100$ ). B: Stromal cells are organized in fascicles (magnification x200). C: Increased cellularity (condensation) is seen adjacent to the epithelium (magnification x200). D: Stromal cells show cytological atypia with nuclear pleomorphism and hyperchromatic nuclei (magnification $\mathrm{x} 400$ ).

Follow up screening mammogram one year after ultrasound guided core needle biopsy showed a $46 \mathrm{~mm}$ mass with an associated clip marker at three o'clock, $13 \mathrm{~cm}$ from the nipple (Figure 4). This mass increased in size when compared with initial screening mammogram a year ago when it measured $15 \mathrm{~mm}$. Given marked interval increase in size of tumor along with biopsy proven fibroepithelial lesion, concern for malignant phyllodes tumor was raised and surgical excision was recommended. Patient underwent surgical consultation followed by lumpectomy which demonstrated borderline phyllodes tumor, intermediate grade (Figure 5). 


\section{Cureus}

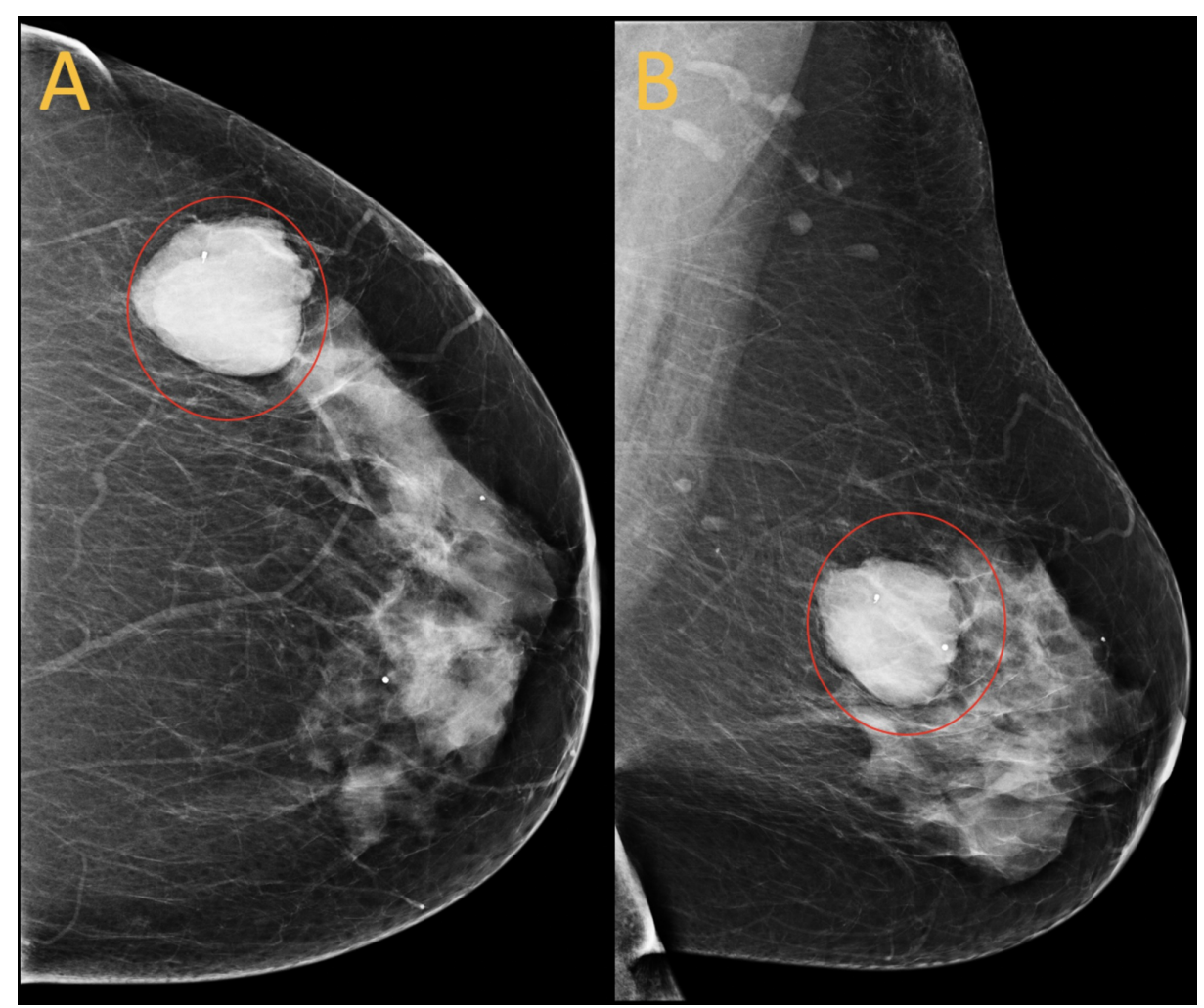

\section{FIGURE 4: Screening mammogram one year later}

A $46 \mathrm{~mm}$ mass containing a biopsy clip is demonstrated at three o'clock, $13 \mathrm{~cm}$ from the nipple (red circles). The mass increased from $15 \mathrm{~mm}$ on the prior mammogram the year before. A mammogram was performed in January 2020.

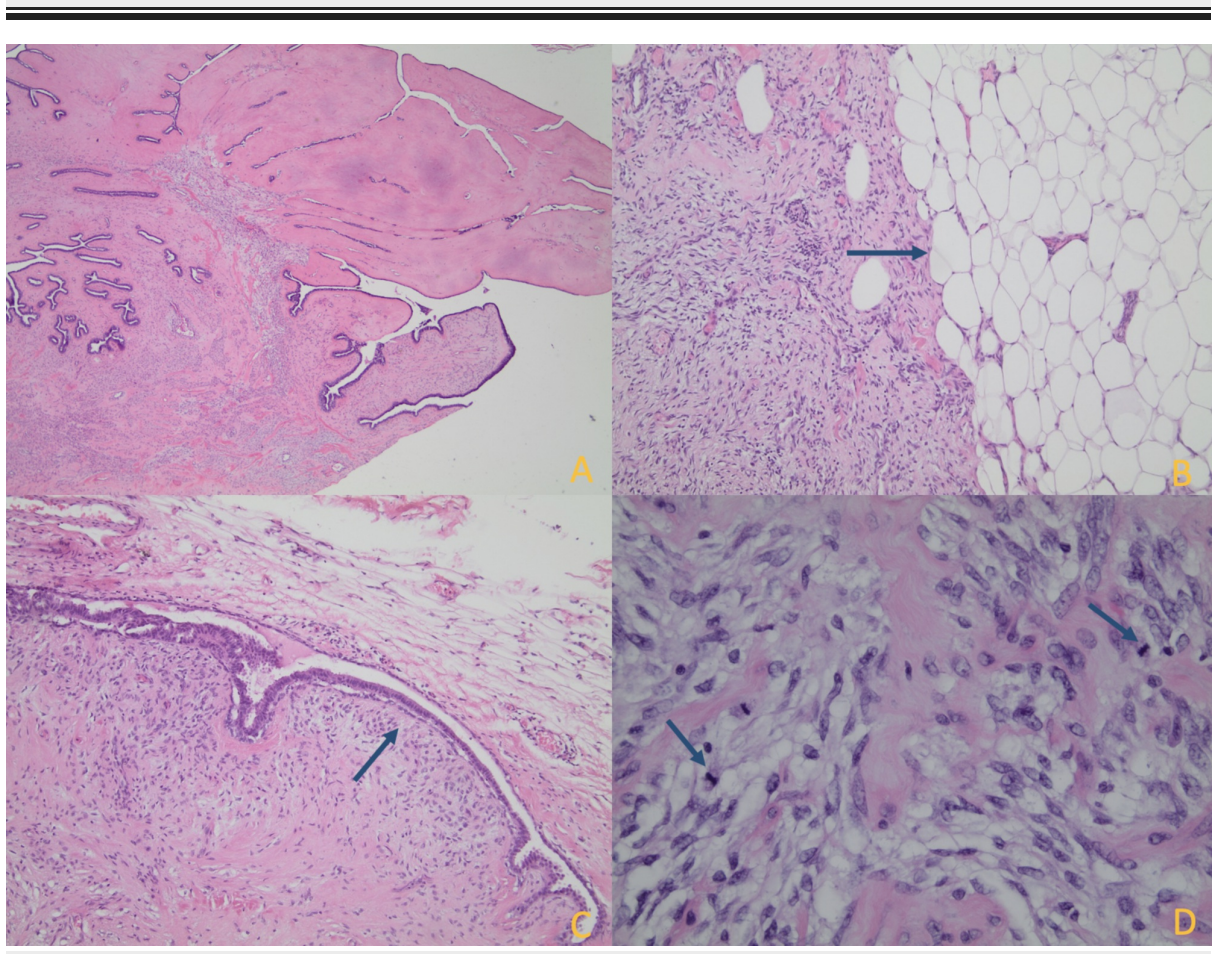

FIGURE 5: Histological findings of lumpectomy of the borderline phyllodes tumor

A: H\&E staining of the mass shows lead-like fronds (magnification $\times 20$ ). B: Tumor invades into the adipose tissue (magnification x100). C: Increased stromal cellularity adjacent to the epithelium (magnification x100). D: Stromal cells show pleomorphic nuclei and mitotic figures (magnification $\times 400$ ). 


\section{Discussion}

The vast majority of phyllodes tumors occur in women, with a median presenting age of 42 to 45 years (range 10 to 82 years). A fibroadenoma is the most common solid breast mass in a woman under the age of 30 but can be seen in older women as well.

The factors that significantly helped to identify phyllodes tumors upon univariable analysis consisted of the presenting symptoms (palpable mass or breast pain), increased size on clinical examination, hyperdense mass on the mammogram, and the following three ultrasound features: heterogeneous echogenicity, presence of round cysts within the mass, and presence of clefts within the mass. The pathologist's suggestion of a phyllodes tumor is also helpful. The symptoms of breast pain, the presence of clefts on ultrasound, the presence of round cysts on ultrasound, and the pathologist favoring of phyllodes tumors from a core needle biopsy specimen are factors that remained statistically significant upon multivariable analysis [9].

Ultrasound findings (clefts and round cysts), suggestive pathological diagnoses, and clinical symptoms are all useful for the decision to surgically remove fibroepithelial lesions diagnosed from the core needle biopsy.

\section{Conclusions}

This case shows the challenge of distinguishing a fibroadenoma from phyllodes tumor on both breast imaging and tissue analysis. In cases where the pathologist reports fibroepithelial lesion and cannot definitively call fibroadenoma on a core needle biopsy sample, a radiologist can help diagnose phyllodes tumor earlier by recommending surgical excision immediately for patients over 40 years old or by recommending short interval follow up imaging in six months to detect interval growth.

\section{Additional Information}

\section{Disclosures}

Human subjects: Consent was obtained by all participants in this study. Conflicts of interest: In compliance with the ICMJE uniform disclosure form, all authors declare the following: Payment/services info: All authors have declared that no financial support was received from any organization for the submitted work. Financial relationships: All authors have declared that they have no financial relationships at present or within the previous three years with any organizations that might have an interest in the submitted work. Other relationships: All authors have declared that there are no other relationships or activities that could appear to have influenced the submitted work.

\section{References}

1. Tan PH, Tse G, Lee A, Simpson JF, Hanby AM: Fibroepithelial tumors. WHO Classification of Tumours of the Breast. Lakhani SR, Ellis IO, Schnitt SJ, Tan PH, van de Vijver MJ (ed): International Agency for Research on Cancer, Lyon, France; 2012. 4:141-147.

2. Tan BY, Tan PH: A diagnostic approach to fibroepithelial breast lesions . Surg Pathol Clin. 2018, 11:17-42. 10.1016/j.path.2017.09.003

3. Zhang Y, Kleer CG: Phyllodes tumor of the breast: histopathologic features, differential diagnosis, and molecular/genetic updates. Arch Pathol Lab Med. 2016, 140:665-671. 10.5858/arpa.2016-0042-RA

4. Tan BY, Acs G, Apple SK, et al.: Phyllodes tumours of the breast: a consensus review . Histopathology. 2016, 68:5-21. 10.1111/his.12876

5. World Health Organization: WHO Classification of Tumours of the Breast. Lakhani SR, Ellis IO, Schnitt SJ, Tan PH, van de Vijver MJ (ed): International Agency for Research on Cancer, Lyons, France; 2012.

6. Krings G, Bean GR, Chen YY: Fibroepithelial lesions; The WHO spectrum. Semin Diagn Pathol. 2017, 34:438452. 10.1053/j.semdp.2017.05.006

7. Tsang AK, Chan SK, Lam CC, Lui PC, Chau HH, Tan PH, Tse GM: Phyllodes tumours of the breast differentiating features in core needle biopsy. Histopathology. 2011, 59:600-608. 10.1111/j.13652559.2011.03939.x

8. Choi J, Koo JS: Comparative study of histological features between core needle biopsy and surgical excision in phyllodes tumor. Pathol Int. 2012, 62:120-126. 10.1111/j.1440-1827.2011.02761.x

9. Wiratkapun C, Piyapan P, Lertsithichai P, Larbcharoensub N: Fibroadenoma versus phyllodes tumor: distinguishing factors in patients diagnosed with fibroepithelial lesions after a core needle biopsy. Diagn Interv Radiol. 2014, 20:27-33. 10.5152/dir.2013.13133 